\title{
Régimen de ahorro individual en Colombia: ¿dónde están las ganancias en eficiencia?*
}

\author{
Flor Esther Salazar Guatibonza
}

\begin{abstract}
Salazar G., F. E. (2010). Régimen de ahorro individual en Colombia: ¿dónde están las ganancias en eficiencia? Revista Activos, 15, 35-71.
\end{abstract}

JEL: J26

Recibido: 2 de noviembre de 2010 Aprobado: 27 de diciembre de 2010

\section{Resumen}

En el régimen de ahorro individual, los trabajadores y empresas realizan afiliación y cotización a través de las administradoras de fondos de pensión (AFP), quienes son las encargadas de la administración de estos fondos, pagan pensiones a través de la modalidad de retiro programado y contratan con compañías de seguros los seguros de invalidez y sobrevivencia y las pensiones bajo la modalidad de renta vitalicia. Por su parte, el Estado es el garante de las pensiones mínimas y asistenciales. Si bien, el régimen de capitalización se propuso como una salida para mejorar las condiciones previsionales de los afiliados y para aminorar las presiones de déficit fiscal, los beneficios y ganancias en eficiencia no parecen ser tan claros para algunos de los actores del mismo.

Artículo de coyuntura y debate

** Contadora Pública y Magíster en Ciencias Económicas de la Universidad Nacional de Colombia. Actualmente se desempeña como docente de tiempo completo en la Universidad Central y es miembro del Observatorio de la Economía Latinoamérica -ODELAC - de la misma universidad. 
Sobre la sostenibilidad del sistema y las debilidades que exhibe, ya son varios los estudios que se han realizado. Lo que se busca con este artículo frente al desempeño de dicho régimen, dieciséis años después de la introducción de la Ley 100 de 1993, es poner en contraste algunos de los resultados que se generaron para dos de los actores en conjunto: el afiliado y las compañías administradoras, a la luz de los argumentos planteados en el momento de su implementación en el país.

\title{
Palabras clave
}

Régimen de ahorro individual, ganancias en eficiencia, resultados AFP

\section{Salazar G., F. E. (2010). Individual savings scheme in Colombia: Where are the efficiency gains? Activos Review, 15, 35-71.}

\begin{abstract}
In individual savings scheme, workers and business carry out affiliations and contributions through the Pension Fund Administrators (AFP), who are responsible for the administration of pension funds, pensions paid through the retirement mode programs and contracts with insurance companies insurance and disability and pensions in the form of an annuity. While the capitalization regime was proposed as a way to improve the pension of the members and to reduce the pressure on fiscal deficit, profits and efficiency gains do not seem so clear to some of the same actors.

On the sustainability of the system and its weaknesses there are several studies that have been made. What this article seeks to address regarding the performance of this system 16 years after the introduction of Law 100 of 1993, is to contrast some of the results that have been generated for both of the following acto is: the member and management companies, in light of the arguments raised at the time of its implementation in the country.
\end{abstract}

\section{Keywords}

System of individual savings, efficiency gains, results AFP 


\section{Salazar G., F. E. (2010). Système d'épargne individuel en Colombie: Où sont les gains d'efficacité? Revue Activos, 15, 35-71.}

\section{Résumé}

Dans le système d'épargne individuel, les travailleurs et entreprises réalisent leurs affiliations et cotisations à travers les Administratrices de Fonds de Pension (AFP), qui sont les entités chargées de l'administration des fonds de pension, paient les retraites à travers la modalité de retrait programmé et contractent auprès des compagnies d'assurances les assurances invalidité et survivants et les retraites sous la modalité de rentes viagères. De son côté, l'Etat est le garant des pensions minimales et d'assistance. Bien que le régime de capitalisation soit proposé comme une solution pour améliorer les conditions de retraite des affiliés et pour réduire les pressions du déficit fiscal, les bénéfices et les gains en efficacité ne paraissent pas être très clairs pour certains des acteurs concernés.

Quant à la durabilité du système et aux faiblesses qu'il laisse voir, de nombreuses études ont déjà été réalisées. L’objectif de cet article, en relation avec le développement de ce système, 16 ans après l'introduction de la loi 100 de 1993, est de contraster quelques-uns des résultats obtenus pour deux des acteurs: l'affilié et les compagnies administratrices, à la lumière des arguments formulés au moment de sa mise en oeuvre dans le pays.

\section{Mots-clé}

Système d'épargne individuel, gain d'efficacité, résultats AFP

\section{Introducción}

En el año 1993 con la Ley 100, Colombia adoptó un sistema de pensiones dual en el cual fue puesto en competencia uno de capitalización individual, administrado por privados con el sistema público de reparto existente, los cuales son excluyentes entre sí. Los esquemas de capitalización se caracterizan porque las condiciones previsionales van a depender de la acumulación de capital que realice la persona, los aportes de los afiliados se administran en una cuenta individual y el valor final de la cuenta también dependerá del manejo financiero vía rentabilidad que produzca. 
En esta vía, al sistema de capitalización se le atribuyeron una serie de beneficios adicionales, tanto para la economía en general como para los afiliados, estimando que sería capaz de superar todas las limitaciones que presentaba el régimen de reparto.

Después de esta reforma, con el fin de reducir el déficit fiscal generado por la transición, en 2003 se aprobó la Ley 797, con la cual se modificaron algunos de los artículos establecidos en la Ley 100 , y cuyas principales disposiciones se orientaron a instaurar como obligatoria la cotización de trabajadores independientes y de personas vinculadas mediante contratos de prestación de servicios, antes considerada como voluntaria; reajustar los términos de traslado de un régimen a otro; limitar la base de cotización; ordenar un incremento gradual de las cotizaciones; incrementar la edad de jubilación, entre otros. Así mismo, con el acto legislativo de 2005 se adelantó la transición al 2010, se eliminaron los regímenes especiales o exceptuados a 2010, y únicamente se mantuvieron los regímenes especiales de la fuerza pública y del presidente de la República, y desde su vigencia eliminó la mesada catorce para los afiliados de tres o más salarios mínimos legales mensuales vigentes (SMLMV) y en el 2011 para los de tres SMLMV o menos.

Sin embargo, ninguna de estas medidas parece haber mejorado las condiciones del sistema y, en la actualidad, ya existen diversos estudios que muestran que los beneficios que inicialmente motivaron la reforma no son tan evidentes y, por el contrario, son muchas las fallas que exhibe el sistema reformado que hacen pensar en la insostenibilidad del mismo a futuro.

Recientemente en declaraciones realizadas, el presidente de la Asociación Colombiana de Administradoras de Fondos de Pensiones y Cesantías (ASOFONDOS) indica sobre la necesidad de una nueva reforma al sistema de pensiones, donde se plantea el aumento en las edades de jubilación, se critica el régimen de prima media y se considera que debería estudiarse la posibilidad de un impuesto a las pensiones más altas. También, en torno a la discusión del plan de desarrollo 2010-2014, se escuchan sugerencias sobre la posibilidad de suprimir el sistema público, pero nada se dice sobre la incapacidad del régimen de ahorro individual para hacer frente al problema previsional, sobre los costos asociados para los afiliados y, mucho menos, dónde se están quedando las ganancias en eficiencia del mismo, si efectivamente las ha tenido. 


\section{Beneficios atribuidos por la reforma desde la perspectiva del afiliado.}

Uno de los objetivos planteados con la introducción de la reforma al sistema de pensiones colombiano lo constituía el aumento de la cobertura del $\mathrm{mismo}^{1}$. Se planteó que el régimen de capitalización individual generaría los incentivos, de tal forma que el afiliado percibiría el hecho de realizar las cotizaciones al sistema no como un impuesto, sino como un mecanismo de ahorro de recursos para su vejez. De esta manera, sería el establecimiento de incentivos en los afiliados lo que permitiría la reducción en los niveles de evasión y el aumento de la fidelidad en los aportes, en beneficio de la ampliación de la cobertura en pensiones.

Bajo esta lógica, desde la perspectiva del afiliado, las altas prestaciones serían una característica del sistema y reforzarían el tema de la generación de los incentivos suficientes para fomentar el ahorro previsional. Para los afiliados y pensionados, el régimen ofrecería mayores pensiones que las del régimen de prima media, no sería un sistema vulnerable al envejecimiento de la población ni a la base asalariada y lograría expandir la protección pensional a la integralidad de trabajadores (Exposición de motivos Ley 100, p. 25).

En términos generales, de acuerdo con la exposición de motivos de la Ley 100, en el sistema propuesto primaría la competencia entre administradoras, que redundaría en mejores servicios con ganancias en eficiencia, bajos precios y mayor rentabilidad de los ahorros, que finalmente se traducirían en unas altas tasas de reemplazo y mejores condiciones pensionales para los afiliados al mismo.

Bajo estas consideraciones y sobre la base de algunos estudios, en esta oportunidad se mostrarán algunas de las condiciones actuales del sistema en términos de cobertura y beneficios pensionales generados para el afiliado, a la vez que se evidencian algunos resultados obtenidos por las administradoras encargadas de la gestión de los fondos, para analizar si efectivamente el sistema exhibe algunas ganancias en eficiencia y si parte de estas se distribuyen hacia los afiliados.

1 Relacionada con los trabajadores que contribuyen al sistema y generan derechos previsionales, y la población que se encuentra recibiendo beneficios previsionales. 


\section{Resultados del sistema frente a objetivos planteados dieciséis años después de la reforma}

\section{Cobertura}

Si bien uno de los principios básicos de la seguridad social es el de la universalidad, en materia de pensiones no se ha logrado garantizar la afiliación a la gran mayoría de la población. En el momento de la reforma se considera que la mayor deficiencia del esquema de reparto era su baja cobertura, que a la fecha de presentación del proyecto de ley se estimaba en un $20 \%$ del total de población; tal falencia esperaba superarse incentivando la afiliación de independientes con capacidad de ahorro. Sin embargo, después de la reforma uno de los problemas del sistema continúa siendo los bajos niveles de cobertura; a 2009 se estima que solo el $31 \%$ de los trabajadores están afiliados a un fondo de pensiones y que únicamente el $25 \%$ de las personas mayores de 60 años recibe una pensión ${ }^{2}$.

Las estadísticas del sistema ${ }^{3}$ muestran que el régimen de ahorro individual cuenta con 8,7 millones de afiliados, mientras que el régimen de prima media tiene 6,4 millones, para un total en los dos esquemas de 15,1 millones de afiliados a pensiones obligatorias. Si bien el régimen de ahorro individual muestra un crecimiento importante en la afiliación, el resultado del sistema en conjunto es mucho menor, y esto se debe a que una proporción importante de afiliados proviene de traslados del régimen de prima media. Del total de afiliados al RAI, a diciembre de 2009, 2.154.226 provinieron del Seguro Social y cajas, esto corresponde aproximadamente al $25 \%$ del total de afiliados, es decir, cerca de una cuarta parte con que cuenta este régimen. En los últimos años, a partir de 2006, la tendencia ha sido de aumento de los traslados del régimen de ahorro individual al de prima media.

Adicionalmente, el total de afiliados no constituye efectivamente la población que se encuentra cotizando al sistema y, como tal, no es un buen indicador para mostrar la cobertura del mismo; de este es necesario descontar el total de personas inactivas ${ }^{4} \mathrm{o}$ población pasiva. Las cifras de afiliados activos a 31 de diciembre de 2009 corresponden a 4,7 millones en el régimen de ahorro individual, aproximadamente el 55\%. Las cifras de afiliados totales y de

2 Esto a partir de los datos estadísticos del sistema reportados por Asofondos y la Superintendencia Financiera de Colombia.

3 Fuente: Asofondos y Superintendencia Financiera de Colombia, a diciembre 31 de 2009.

4 Se considera inactivos aquellos que no han cotizado al sistema durante los últimos seis meses a la fecha de medición para afiliados dependientes, o en los últimos tres meses para afiliados independientes. 
afiliados activos muestran que el incremento esperado en la cobertura no se logra, y que en la práctica tan solo cerca de la mitad de ellos son contribuyentes activos del sistema.

Por otra parte, si se consideran los afiliados cotizantes, que son aquellos que se encuentran al día en sus cotizaciones a la fecha respectiva (mientras que los activos corresponden a aquellos que han realizado cotización alguna en los últimos seis meses), se tiene que a diciembre de 2009 únicamente el 45\% del total de los afiliados efectivamente cotizó al sistema, es decir que se tenía un 55\% de no cotizantes, e históricamente la proporción de cotizantes ha sido inferior. La relación entre afiliados y aportantes permite pensar que las densidades de cotización son muy bajas, situación que puede ocasionar que una proporción importante no logre acumular el capital para financiar su propia pensión dadas las características de los esquemas de capitalización individual, en donde la acumulación de saldos de capital es el determinante de los beneficios pensionales, y los periodos de inactividad, en los que no se realizan aportes, pueden tener un efecto altamente negativo en el logro de tal objetivo.

En términos de la poblacion económicamente activa, a diciembre de 2009 el total de afiliados activos al RAI corresponde aproximadamente a un 22\% de la PEA $^{5}$; si se toman los dos regímenes (RAI y RPM), se tiene que los afiliados activos son el 32\%, relación que muestra una baja cobertura. Así mismo, respecto de la cobertura efectiva, esto es si se considera a los afiliados cotizantes, el número está alrededor del 18\%.

Figura 1. Cobertura efectiva del sistema de pensiones

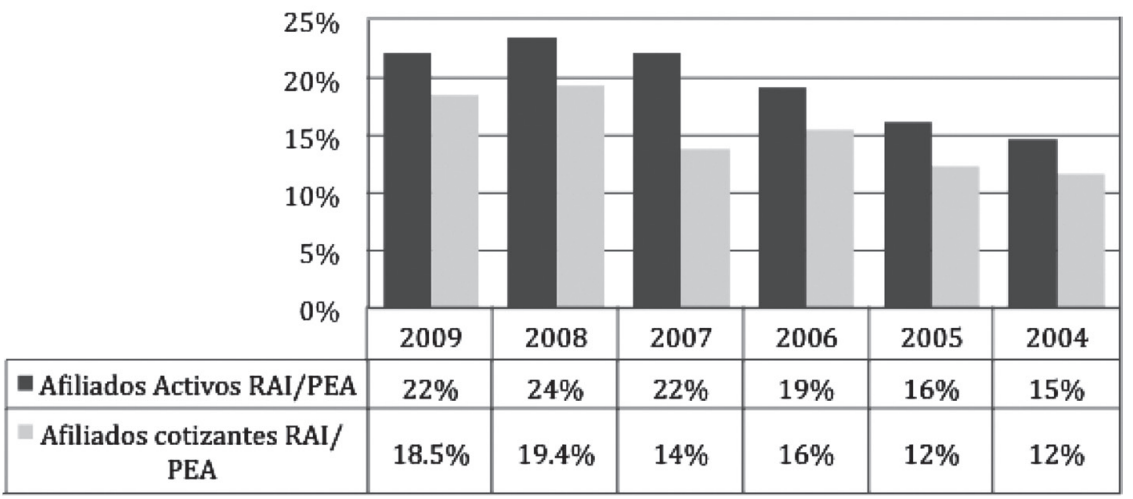

Fuente: Estadísticas Asofondos 
Después de dieciséis años de implementada la reforma, no es posible observar que las condiciones hayan mejorado ostensiblemente y que en materia de cobertura se hayan logrado las metas esperadas. En torno a los argumentos de la generación de incentivos para el ahorro de recursos para la vejez, se puede plantear que no necesariamente el establecimiento de una relación directa entre cotizaciones-beneficios genera mayores niveles de ahorro y por tanto mayor cobertura. Los problemas de afiliación refieren a condiciones estructurales del mercado laboral y de la distribución del ingreso de la población del país. La precarización del empleo, los altos niveles de desempleo e informalidad, conducen a desvirtuar el supuesto acerca de la generación de mejores pensiones vía capitalización.

Así mismo, no es posible creer que las personas que tienen bajos ingresos y se cuentan dentro de la línea de pobreza durante toda su vida vayan a lograr ahorrar el capital necesario para soportar los ingresos que les permitan tener una vejez digna. Los mecanismos de incentivos tendrían algún efecto solo en la medida en que se tenga capacidad de pago, esto es, personas con ingresos suficientes, situación que no es la de la mayoría de la población del país donde, en términos de ingresos, el $45,5 \%$ se encuentra en niveles de pobreza y el $16,4 \%$ en condiciones de indigencia ${ }^{6}$. De igual manera, los niveles de informalidad y periodos de desempleo generan bajas densidades de cotización que tampoco contribuyen al proceso de acumulación de capital; se estima que sólo el $20 \%$ de los afiliados cotizan durante el $90 \%$ o más de su vida laboral.

Suárez y Acosta (2007) encuentran que una de las causas de la debilidad de la cobertura del sistema pensional es la baja generación de empleo formal. Así mismo, logran establecer que la cobertura depende del nivel de educación, que es un determinante de la afiliación, en tanto que las personas con educación superior a los 16 años tienen tasas de afiliación cercanas al 66\%, para los de menor educación la afiliación está por debajo del $10 \%$.

En un estudio comparativo en términos de cobertura de los sistemas de pensiones en Colombia, Chile y México, Aguila, Attanasio y Quintanilla (2010) encuentran que:

La probabilidad de cotizar es significativamente creciente con el nivel educacional en Chile y Colombia. En Chile, la probabilidad de cotizar aumenta, respectivamente, en un $7 \%, 12 \%$ y $17 \%$ para los individuos con educación primaria, secundaria/ bachillerato y universidad respecto de aquellos sin educación (categoría omitida). Las diferencias son aún más dramáticas en Colombia: la probabilidad de cotizar 
aumenta en un 14\%, 32\% y 59\% para aquellos con educación primaria, secundaria/ bachillerato y universidad, respectivamente. Por el contrario, en México sólo los individuos con primaria tienen mayor probabilidad de cotizar en el sistema de pensiones pero no se observan diferencias para otros niveles educacionales (p. 27).

Este estudio también muestra que de los tres países analizados, Colombia es el que exhibe la más baja tasa de cobertura pese a haber hecho obligatoria en 2003 la afiliación y el pago de aportes de los trabajadores independientes, que en Chile y México son voluntarios.

La cobertura del sistema previsional con respecto a la PEA en 2005 fue del $62 \%$ en Chile, del 25,6\% en Colombia y del 36,3\% en México.

A pesar de la sustancial variabilidad entre los tres países, las bajas tasas reflejan que la cobertura sigue siendo un problema incluso después de que los sistemas de pensiones fueron reformados (Aguila, Attanasio y Quintanilla, 2010, p. 35).

Si se mira la tendencia de afiliación al sistema respecto a la composición según dependencia del trabajador, en promedio desde que inició el RAI, el 5\% del total de afiliados corresponde a personas independientes, la mayor parte continúa siendo población con relación laboral, concentrándose en el sector formal y población no pobre. Así, si se parte de que los niveles de informalidad del país alcanzan el 52\% de la población ocupada ${ }^{7}$, lo que se evidencia son los bajos niveles de cobertura en la población trabajadora que no presenta vinculación laboral dependiente.

De acuerdo con el informe presentado por el DANE, según encuesta continua de hogares para el segundo trimestre de 2009, apenas el 10,5\% de la población informal se encuentra afiliada al sistema de pensiones. 
Tabla 1. Composición de los afiliados al RAI según dependencia del trabajador

\begin{tabular}{|c|c|c|c|c|}
\hline Año & Dependientes & Independientes & Total & $\begin{array}{c}\text { \% participación } \\
\text { independientes }\end{array}$ \\
\hline 1994 & 831.635 & 159.985 & 991.620 & $16 \%$ \\
\hline 1995 & 1.582 .677 & 134.045 & 1.716 .722 & $8 \%$ \\
\hline 1996 & 1.935 .036 & 97.369 & 2.032 .405 & $5 \%$ \\
\hline 1997 & 2.397 .520 & 96.843 & 2.494 .363 & $4 \%$ \\
\hline 1998 & 2.813 .188 & 95.445 & 2.908 .633 & $3 \%$ \\
\hline 1999 & 3.337 .620 & 105.703 & 3.443 .323 & $3 \%$ \\
\hline 2000 & 3.832 .819 & 121.188 & 3.954 .007 & $3 \%$ \\
\hline 2001 & 4.216 .673 & 119.706 & 4.336 .379 & $3 \%$ \\
\hline 2002 & 4.597 .452 & 118.496 & 4.715 .948 & $3 \%$ \\
\hline 2003 & 4.629 .293 & 118.608 & 4.747 .901 & $2 \%$ \\
\hline 2004 & 5.109 .377 & 142.837 & 5.252 .214 & $3 \%$ \\
\hline 2005 & 6.121 .136 & 240.627 & 6.361 .763 & $4 \%$ \\
\hline 2006 & 6.717 .775 & 292.512 & 7.010 .287 & $4 \%$ \\
\hline 2007 & 7.453 .768 & 360.767 & 7.814 .535 & $5 \%$ \\
\hline 2008 & 7.971 .828 & 596.446 & 8.568 .274 & $7 \%$ \\
\hline 2009 & 7.928 .111 & 813.545 & 8.741 .656 & $9 \%$ \\
\hline & & & & \\
\hline
\end{tabular}

Fuente: Superintendencia Financiera de Colombia

Si bien las condiciones estructurales de trabajo son determinantes, el problema tampoco es solo del mercado laboral; los estudios evidencian que el esquema de capitalización individual no se muestra suficiente para responder por el tema de las pensiones previsionales.

\section{Rentabilidad de los fondos frente a exigencia de rentabilidad mínima y riesgo para el afiliado}

En un esquema como el régimen de ahorro individual, las rentabilidades generadas en el manejo de los fondos son determinantes para el capital de pensión que el afiliado logre acumular. Se plantea que más de la mitad de la pensión que alcanza a acumular un afiliado se debe a la capitalización y una parte menor a sus aportes. Por tanto, el componente principal de la pensión es la capitalización que se obtiene dada una tasa de retorno del portafolio (Martínez y Murcia, 2008, p. 1). 
En los inicios del sistema, las rentabilidades obtenidas parecían confirmar algunos de los supuestos introducidos con la reforma; no obstante, considerando que las rentabilidades de los fondos están sujetas al comportamiento de los mercados financieros, en los últimos años se ha presentado una tendencia a la baja teniendo los afiliados que asumir en algunos casos tasas negativas. Las rentabilidades de los fondos de pensiones se presentan para un periodo móvil de 36 meses, lo que suaviza los resultados obtenidos en periodos en los que se generan fuertes pérdidas. Un ejemplo de esto son las caídas experimentadas en los años 2006, 2007 y primeros meses del 2008. En el 2006 las pérdidas de los fondos fueron aproximadamente de 3,38 billones de pesos y en el 2007 alcanzaron los $\$ 770.000$ millones, aproximadamente seis meses de las cotizaciones efectuadas por los afiliados en los dos últimos años. A comienzos de 2008, dada la volatilidad de los mercados internacionales, los fondos se vieron fuertemente impactados con tasas negativas de rentabilidad; los resultados durante el primer trimestre muestran que los fondos perdieron alrededor de 5,2 billones, podría decirse que el equivalente a siete meses de cotización.

Bajo la metodología $\mathrm{NAV}^{8}$, Asofondos (2010, p. 2) estima que "la rentabilidad histórica nominal en los quince años de existencia del régimen de ahorro individual con solidaridad ha sido de 17,56\% nominal anual. Este resultado ha sido complementado con menores tasas de inflación, lo que ha permitido alcanzar una rentabilidad histórica de $10,12 \%$ real anual". Esta rentabilidad es mucho menor si se consideran los niveles de rentabilidad que estaría obteniendo el afiliado neto de comisiones.

La norma establece que las administradoras de fondos de pensiones deberán garantizar un nivel de rentabilidad mínimo ${ }^{9}$. Al respecto, existe el riesgo de lo que se ha denominado "el comportamiento manada", que consiste en que los portafolios de inversión de las distintas administradoras son poco diferenciados.

8 Metodología para calcular la rentabilidad, según el cambio en el valor de la unidad del fondo. Las unidades miden el valor de los aportes de los afiliados y representan cuotas parte del valor patrimonial del fondo. El mayor valor de la unidad representa los rendimientos que se han obtenido.

$\mathrm{VU}=\mathrm{VFF} / \mathrm{UN}$, donde NU: número de unidades, VFF: valor del fondos al cierre del día.

NU = NUI + NUIC - NUIR, con NUI: número de unidades al inicio del día, NUIC: número de unidades compradas en el día, NUIR: número de unidades retiradas por todos los conceptos (circular básica contable, Superintendencia Financiera de Colombia).

9 El Decreto 2664 del 12 de julio de 2007 modifica el artículo 2 del Decreto 1592 de 2004, que establece la forma en que se determinará el nivel de rentabilidad mínima. De acuerdo con esto, el nivel de rentabilidad mínima se obtiene como el promedio simple disminuido en un $30 \%$ de: el promedio ponderado de las rentabilidades acumuladas efectivas anuales de las AFP, y el promedio ponderado de: la variación porcentual del índice de la bolsa de valores de Colombia ponderado por el porcentaje del portafolio invertido en acciones de emisores nacionales, la variación porcentual efectiva anual del índice representativo del mercado accionario del exterior ponderado por el porcentaje del portafolio de los fondos invertidos en acciones de emisores extranjeros y la rentabilidad efectiva anual del portafolio de referencia ponderado por el porcentaje invertido en las demás inversiones. 
Esto se manifiesta en los niveles de rentabilidad generados por los fondos que son muy similares.

El efecto manada no es en sí mismo un inconveniente cuando los portafolios son similares pero bien diversificados; cuando ello ocurra, los grandes beneficiados son los afiliados al sistema. Sin embargo, no protege a los afiliados contra el riesgo de pobre desempeño, pues la referencia al promedio de los administradores no permite evidenciar una mala gestión por parte del sistema, ni motiva a los administradores a efectuar una adecuada evaluación de la ecuación riesgo-retorno al momento de realizar una inversión, pues para cumplir con la rentabilidad mínima solo bastaría con seguir el comportamiento de los demás (Borrero: 2003, p. 26).

Figura 2. Rentabilidad de los fondos de pensión vs. rentabilidad mínima (periodo móvil de 36 meses)

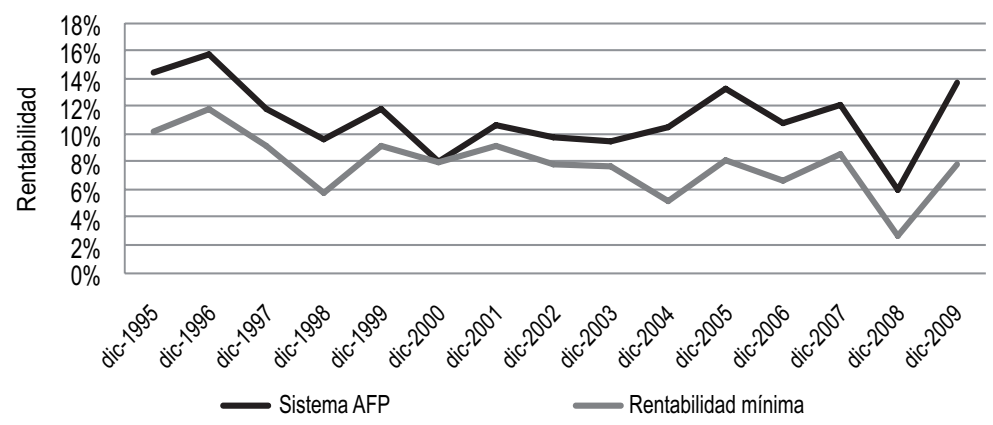

Fuente: Superintendencia Financiera de Colombia. Informes rentabilidad fondos de pensiones obligatorias

En términos de la distribución de las inversiones de los fondos, a julio de 2010 el 42,4\% del portafolio se encuentra invertido en recursos de deuda pública (figura 3) e históricamente esta ha sido la tendencia. 
Figura 3. Distribución inversiones portafolio fondos de pensiones julio de 2010

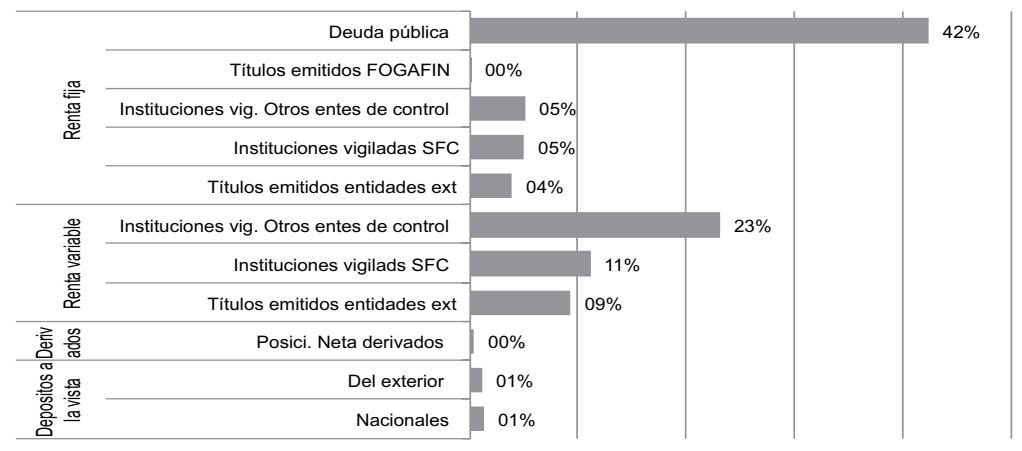

\section{Fuente: Superintendencia Financiera de Colombia}

Una parte importante de los fondos ha sido invertida en títulos de renta fija, con una importante concentración en el uso de recursos por parte del Estado mediante la colocación de TES; es así como en busca de generar mayores rentabilidades haciendo más agresiva la inversión de los recursos para pensión en el mercado de capitales, en 2009 mediante la Ley 1328 se establece la creación de la figura de multifondos, del sistema de ahorro voluntario para la vejez y los beneficios económicos periódicos (Beeps), que entrará en vigencia en 2011 y aplica únicamente para quienes cotizan a los fondos privados de pensiones. Lo que busca la reforma es la diferenciación de fondos de acuerdo con el nivel de riesgo que se asuma en las inversiones de los mismos, de tal manera que al tomar mayor riesgo, especialmente en el caso de los afiliados jóvenes, se logren mayores niveles de rentabilidad. Es así como existirán tres tipos de fondos: el agresivo, para los trabajadores más jóvenes, con un portafolio con inversiones en renta variable hasta del $70 \%$, y el resto en otros papeles como CDT y TES. El moderado, para personas entre los 35 y 45 años, compuesto por acciones hasta por el $40 \%$ de renta variable. Finalmente, el conservador, el cual podrá destinarse sólo en un $20 \%$ a renta variable, ya que será para personas entre los 55 y 60 años.

Si bien la norma busca dar mayores opciones de rentabilidad al ahorro pensional, el trabajador será el único que podrá elegir alguno de los tipos de fondos. Frente a esto, dadas las asimetrías de información, no todos los afiliados al sistema tendrán los criterios y la información para tomar la mejor elección y nuevamente es el individuo el que no solo asumirá de manera individual su riesgo, sino que estará expuesto en un mayor grado en 
la búsqueda de unos mejores resultados de jubilación. Se fortalece así la dependencia del comportamiento de los mercados financieros, y la seguridad social en pensiones que debiera dar seguridad no se torna tan segura, como es la característica natural de este esquema.

\section{Beneficios pensionales}

Cuando se habla de los beneficios generados para los afiliados, adicional a la cobertura y rentabilidades sobre las cuentas individuales, un factor fundamental hace referencia a las pensiones y monto de las mismas que se puedan obtener dentro del sistema en el momento de la jubilación, que a la vez están determinados por los dos anteriores.

La ley establece las condiciones bajo las cuales un afiliado puede hacerse acreedor al derecho de una pensión. De acuerdo con el artículo 64 de la Ley 100 de 1993 en cuanto a los requisitos para tener el derecho a pensión, se establece:

Los afiliados al régimen de ahorro individual con solidaridad, tendrán derecho a una pensión de vejez, a la edad que escojan, siempre y cuando el capital acumulado en su cuenta de ahorro individual les permita obtener una pensión mensual, superior al 110\% del salario mínimo legal mensual vigente a la fecha de expedición de esta ley, reajustado anualmente según la variación porcentual del índice de precios al consumidor certificado por el DANE.

Para el cálculo de dicho monto se tendrá en cuenta el valor del bono pensional, cuando a este hubiere lugar [...] (artículo 64, Ley 100 de 1993).

Adicionalmente, en el artículo 66 de la misma ley se establece la posibilidad de devolución de saldos:

Quienes a las edades previstas no hayan cotizado el número mínimo de semanas exigidas, y no hayan acumulado el capital necesario para financiar una pensión por lo menos igual al salario mínimo, tendrán derecho a la devolución del capital acumulado en su cuenta de ahorro individual, incluidos los rendimientos financieros y el valor del bono pensional, si a este hubiere lugar, $\mathrm{o}$ a continuar cotizando hasta alcanzar el derecho ${ }^{10}$. 
Así mismo, cumplidos los requisitos en el momento de jubilación, el afiliado puede optar por una de las modalidades de pensión: renta vitalicia inmediata, retiro programado o retiro programado con renta vitalicia diferida ${ }^{11}$.

Referente al número de pensiones, a diciembre de 2009 el sistema ha otorgado 36.195 pensiones, de las cuales únicamente 7.314 son de vejez, 8.665 de invalidez y 20.216 de sobrevivencia (figura 4). De acuerdo con un informe financiero de la Contraloría General de la República (septiembre de 2008) sobre el régimen de ahorro individual, se establece que esta tendencia en las pensiones otorgadas por el sistema revela la disminución del disfrute directo por parte del afiliado a favor de los sobrevivientes al estar demasiado cerca el reconocimiento con la esperanza de vida. Hechos que alertan para no insistir en el aumento de la edad de jubilación (p. 53).

Figura 4. Pensiones por modalidad y riesgo otorgadas por el RAI a 2009

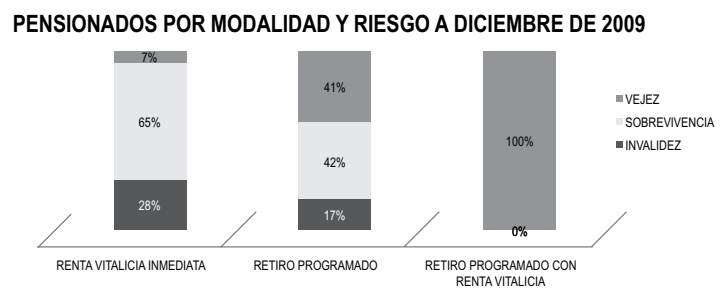

Fuente: Superintendencia Financiera de Colombia

11 * Renta vitalicia inmediata. Modalidad de pensión mediante la cual el afiliado o beneficiario contrata directa e irrevocablemente con una aseguradora el pago de una renta mensual hasta su fallecimiento, y el pago de pensiones de sobrevivientes en favor de sus beneficiarios hasta que mantengan dicha calidad. Tales pensiones deben ser uniformes en términos de poder adquisitivo constante y no pueden ser contratadas por valores inferiores a la pensión mínima vigente (AIOS: 2003, 123).

* Retiro programado. Es la modalidad de pensión en la cual el afiliado o beneficiario obtiene su pensión de la administradora con cargo a su cuenta individual y al bono pensional, si hubiera lugar. Para el efecto, se calcula cada año una anualidad en unidades de valor constante igual al resultado de dividir el saldo de su cuenta individual y bono pensional, por el capital necesario para financiar una unidad de renta vitalicia para el afiliado y sus beneficiarios. La pensión mensual corresponderá a la doceava parte de dicha anualidad. A la muerte del afiliado, si no hubiese beneficiarios, el saldo de la cuenta se transfiere a la masa sucesoral. Si no hubiese causahabientes, el saldo se destina a financiar la garantía de pensión mínima (AIOS: 2003, 123).

* Retiro programado con renta vitalicia diferida. Es la modalidad por la cual un afiliado contrata con la aseguradora de su elección una renta vitalicia, con el fin de recibir pagos mensuales a partir de una fecha determinada, reteniendo en su cuenta individual de ahorro pensional los fondos suficientes para obtener de la administradora un retiro programado, durante el periodo que medie entre la fecha en que ejerce la opción por esta modalidad y la fecha en que la renta vitalicia diferida comience a ser pagada por la aseguradora. La renta vitalicia diferida contratada no podrá ser inferior a la pensión mínima de vejez vigente (AIOS: 2003,123). 
Si se habla de la cobertura en jubilación, es decir pensionados del sistema sobre población en edad de pensionarse, esta apenas alcanza un 26\% (Fedesarrollo, 2010), con una amplia concentración en el régimen de prima media, puesto que a diciembre de 2009 de los pensionados totales sólo el 3,9\% correspondía al RAI (figura 5).

Figura 5. Población mayor de 65 años $v s$. pensionados ISS y RAI

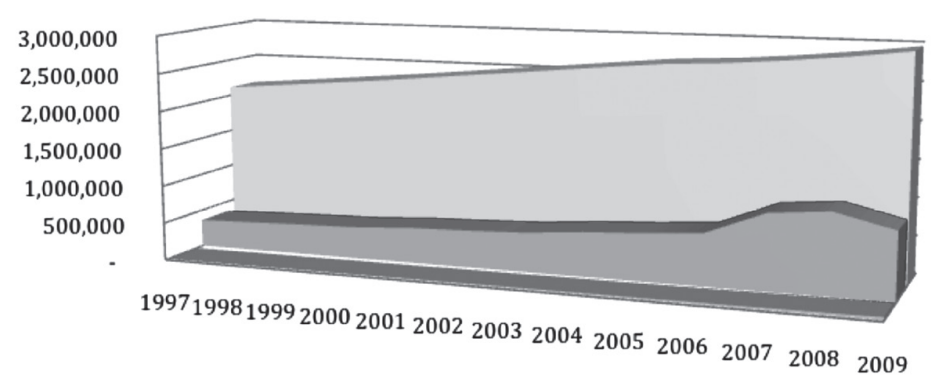

" Pensionados RAI $\quad$ Pensionados ISS Población mayor de 64 años

Fuente: Datos población: DANE, pensionados: estadísticas Asofondos

Aunque el crecimiento de los pensionados en el régimen de ahorro individual es significativo, el número de pensionados contrasta con el de población vieja beneficiaria de asistencia subcuenta de solidaridad, $224.344^{12}$, y los pensionados que corresponden al régimen de prima media.

Esta situación, más algunos estudios sobre la sostenibilidad y proyecciones del sistema ${ }^{13}$, plantean que bajo las actuales condiciones de desenvolvimiento del mismo puede presentarse que un gran número de cotizantes no alcancen a acumular el capital necesario para pensión y tengan que recurrir a la garantía de pensión mínima, o, lo que es peor, ni siquiera reúnan las condiciones necesarias para la garantía y por el contrario deban recurrir a la asistencia del Estado, que es lo que se evidencia con el volumen de beneficiarios de la subcuenta de solidaridad del fondo de solidaridad pensional. Es un tema que debe analizarse y tomarse en cuenta en las decisiones de política en materia de seguridad social en pensiones, pero no es el objetivo detenerse en este asunto en el presente análisis.

13 Arias, M. \& Mendoza, J.C. (2009). Un modelo de simulación del régimen pensional de ahorro individual con solidaridad en Colombia; Reveiz, León y Piraquive. (2009). Modelo de simulación del valor de la pensión de un trabajador en Colombia. 
Como característica natural del esquema, independiente de la modalidad de pensión que el afiliado elija, los montos que obtenga estarán directamente relacionados con el saldo de capital acumulado en su cuenta individual, las tasas actuariales, tablas de sobrevivencia, las características del afiliado y su grupo familiar, y los costos cobrados por la aseguradora o administradora. Dentro de los argumentos para la introducción del esquema de capitalización individual se mencionaba la obtención de mejores pensiones respecto al sistema existente antes de la reforma. Sobre este tema, es difícil establecer algún tipo de comparación, por cuanto muchas de las pensiones otorgadas por el RAI se han financiado con recursos obtenidos del bono pensional del sistema anterior.

Sin embargo, en cuanto a niveles de pensión y tasas de reemplazo ${ }^{14}$, en un estudio realizado por el BBVA (2009) se establece que

se tendrían tasas de reemplazo modestas, las cuales se incrementarían en cerca del $30 \%$ entre el 2015 y el 2050, de niveles iniciales de $34 \%$, y podrían llegar a $42 \%$ en el 2030 y luego al 43\% en el 2050 (p. 112). Este estudio también establece que más del 70\% de las rentas vitalicias vigentes en la actualidad son equivalentes a menos de dos salarios mínimos (BBVA, 2009, p. 138).

En materia de simulación de resultados del régimen de ahorro individual, también se tienen estudios como el de Reveiz, León y Piraquive (2009), que busca simular el valor de la pensión de un trabajador en Colombia. Este trabajo señala que, en promedio, los hombres que se encuentran en los cuatro primeros deciles y aquellos que están en la parte baja de la distribución del quinto decil no podrán obtener la pensión mínima (un SMM) y, por sus bajas densidades de cotización, no cumplirán con las semanas requeridas para tener el derecho a la GPM (p. 20). Cabe indicar que en el decil cinco se ubican personas que realizan cotizaciones sobre 1,5 salarios mínimos, la gran mayoría de la población afiliada al sistema, proporción que estaría por encima del $70 \%$.

Para mencionar otros estudios que permiten analizar las condiciones del RAI, se tiene un modelo de simulación del régimen, desarrollado por Arias y Mendoza (2009), cuyo objetivo fue proyectar la dinámica del sistema durante los siguientes cuarenta años. A partir de las estimaciones realizadas, el trabajo encuentra resultados como los siguientes: el ingreso base de liquidación (promedio salarial de los últimos diez años). 
- En términos del ingreso que van a recibir los pensionados, medido en función de la tasa de reemplazo, se observa que en promedio esta presenta niveles inferiores al 50\% (p.39).

- Dentro de los principales resultados se encontró que alrededor del $80 \%$ de los afiliados tienen ingresos inferiores a dos SMLV. Considerando las bajas densidades de cotización que presenta esta población, se convierte en un gran desafío para el sistema el cubrimiento de estos afiliados en su etapa de jubilación (p. 43).

En términos generales, todos los estudios sobre la viabilidad y sostenibilidad del sistema tienen como puntos de encuentro las dificultades que este presenta en cuanto a cobertura, generación de los beneficios adecuados que puedan brindar posibilidades de una vida digna a la gran mayoría de población afiliada, que corresponde a cerca del $80 \%$, y sobre todo hacen evidente la necesidad de repensar el sistema y revisar el componente solidario del mismo.

$\mathrm{Al}$ evaluar los beneficios del régimen para el afiliado es importante mencionar que es él quien de manera individual debe soportar el riesgo que el sistema involucra y los costos generados por este.

La inclusión del esquema de cuentas individuales involucra cambios tanto en los beneficios como en el riesgo de los beneficios esperados. Las cuentas individuales aumentan la incertidumbre y variabilidad de los beneficios, incertidumbre frente a futuros ingresos e incertidumbre frente a variables como la inflación, lo que hace que los beneficios bajo este esquema sean altamente inciertos (Harris, Sabelhause y Simpson, 2005).

Este es el caso de las altas pérdidas asumidas por los fondos en los años 2006, 2007 y primeros meses del año 2008. Por lo anterior, no es posible establecer que el esquema de capitalización va a generar beneficios pensionales superiores a los del régimen de reparto.

Las reformas que introdujeron esquemas de capitalización individual recurrieron como fundamento a la teoría de incentivos argumentando la necesidad de generar responsabilidad en el individuo en la previsión de los ingresos para su vejez, y ahora se introdujo el esquema de multifondos. No obstante, es preciso contar con que no se trata únicamente de generar los incentivos para el ahorro, sino que el individuo debe enfrentarse a una serie de riesgos relacionados con las condiciones del mercado laboral, el comportamiento macroeconómico y los resultados de las inversiones de sus fondos, los cuales dependen del juego de los mercados financieros que pueden generar ganancias, como también la pérdida 
de los ahorros de la cuenta. Elementos que en condiciones de alteración difícilmente le permitirán al individuo una adecuada previsión de ahorros para su vejez.

Así, para el afiliado, el sistema de seguridad social en materia de pensiones está impregnado por un alto grado de inseguridad y desigualdad, por cuanto en términos de equidad las tasas de retorno no van a ser las mismas en el tiempo para individuos con características similares, y para las generaciones los niveles de pensión van variar de acuerdo con las condiciones del entorno económico que afectan los rendimientos financieros que se puedan generar para la cuenta individual. Así mismo, no se puede considerar que tenga las mismas necesidades de protección social un individuo con un nivel de salario mínimo que uno con ingresos superiores a los dieciséis salarios mínimos para que deba asumir los mismos riesgos, como tampoco tiene las mismas posibilidades de ahorro y de hacerse beneficiario de una pensión de jubilación.

De otra parte, los costos asumidos por las cuentas individuales, en términos de las comisiones efectivas que se les aplican a los fondos acumulados, se consideran elevados (Salazar, 2008). Algunos estudios ya han planteado como crítica a los esquemas privados de cuentas individuales lo elevado de los costos de administración no solo en el caso colombiano, sino en países como Chile, Reino Unido, México. Del 16\% del aporte en 2009, únicamente se abona a la cuenta del afiliado el 11,5\%. Sin entrar a analizar el costo efectivo asumido por el afiliado en términos de pérdida de rentabilidad, podría argumentarse que los costos aplicados son elevados porque efectivamente la administración de este tipo de recursos genera gastos elevados, o porque las ganancias de las administradoras también son elevadas. En esta línea, a continuación se presentan algunos resultados del desempeño de las administradoras de fondos de pensiones y de las compañías de seguros con quienes se contrata el pago de pensiones, lo que permitirá obtener algunas conclusiones respecto a la distribución de ganancias en eficiencia en la operación del sistema.

A precios de 2009, durante los últimos diez años el sistema ha recibido por aportes 81,6 billones de pesos, y las pensiones en este mismo periodo son aproximadamente de 2,0 billones pagados por las AFP y 4,9 billones por las aseguradoras, lo que representa apenas un 3\% de las pensiones pagadas por el régimen de prima media. Así mismo, en el periodo 1995-2007 (no se dispone de datos más recientes) han sido emitidos por la nación cerca de 359.086 bonos con un valor cercano a los 12,4 billones y pagados 22.118 bonos por 1,9 billones, esto muestra que una parte importante de las pensiones otorgadas por el régimen de ahorro individual se han financiado con recursos provenientes del bono de reconocimiento, por lo que no sería consistente afirmar que este sistema genera mejores 
beneficios. Así mismo, mientras que vía presupuesto de la nación se soportan los gastos de transición, los resultados para las AFP se muestran claramente satisfactorios.

\section{Estructura del mercado de AFP e indicadores de resultados para las mismas}

En el esquema de capitalización individual se distinguen dos tipos de operadores, las administradoras de los fondos de pensiones, AFP, y aquellas instituciones con quienes se contratan los seguros. Generalmente, los indicadores del sistema se realizan con relación a los fondos administrados; no obstante, en este aparte se analizarán algunos de los resultados en términos de indicadores de operación de las AFP en su tarea de recaudación y gestión de fondos y de las compañías aseguradoras con quienes se contratan los seguros previsionales, a la luz de las condiciones en que se encuentran los afiliados.

\section{Administradoras de fondos de pensiones en Colombia}

En el inicio del sistema en el año 1995, eran trece las AFP ${ }^{15}$ que entraron al mercado; en la actualidad, operan seis administradoras de fondos de pensiones y cesantías: Colfondos, Porvenir, Protección, ING, Horizonte y Skandia. A marzo de 2010, Porvenir del grupo AVAL cuenta con el 31\% de los afiliados del régimen de ahorro individual, el 22\% Protección, Horizonte con el 18\%, Colfondos con el 16\%, ING con el 12\% y en el último lugar Skandia con el $1 \%$ de los afiliados del régimen.

Diversos estudios sobre las características del mercado de pensiones indican que la concentración ha sido una constante en los países que implementaron sistemas de cuentas individuales con administración privada, como es el caso de la mayoría de países de América Latina.

El Banco Mundial ha encontrado fallas serias en la competencia: i) la industria es oligopólica y tiene una clientela cautiva cuyas cotizaciones son retenidas hasta que se retiran los asegurados; ii) hay una alta y creciente concentración que es preocupante y puede serlo aún más en el futuro; iii) con el fin de reducir los gastos de operación, las restricciones al número de veces por año que un asegurado puede

Las AFP se constituyen en tipo especial de intermediario financiero por cuanto las contribuciones son de carácter obligatorio, permanecen largo plazo en el sistema y están dadas para un fin específico, teniendo en cuenta que no es posible disponer del capital acumulado hasta no cumplir los requisitos establecidos. 
cambiarse de administradora han institucionalizado lo que antes era un oligopolio de hecho y hacen evidente la confabulación y el desarrollo de un cartel poderoso; iv) la evidencia de América Latina claramente demuestra que la competencia entre las administradoras por parcelas de mercados que son relativamente pequeños sólo genera comisiones más altas, y v) la industria de fondos de pensiones en la región es cualquier cosa menos un buen ejemplo de competencia (Gill, Packard y Yermo, 2003, pp. 43-44, 112, 174 y 176, en Mesa Lago, Evaluación de un cuarto de siglo de reformas: 2004, p. 11).

Dentro de los beneficios de la introducción de esquemas de capitalización individual se consideraba que el manejo de los recursos de pensión por parte de administradoras privadas redundaría en una reducción de los costos administrativos vía libre competencia en el mercado. Sin embargo, la literatura existente sobre el tema encuentra que en América Latina la competencia no se ha dado como se planteaba y los sistemas se caracterizan por concentración de la actividad en unas pocas administradoras con ganancias en términos de eficiencia, las que finalmente no se transmiten a los usuarios, sino que las mismas administradoras se apropian.

Para determinar si hay espacio para bajar precios y traspasar utilidades desde los productores a los consumidores, es necesario evaluar dos elementos clave: la existencia de barreras a la entrada y la intensidad de la competencia. El mercado de las AFP se caracteriza tanto por barreras a la entrada como por escasa intensidad de la competencia (Marcell, 2006, p. 53).

A pesar de que en Colombia, dentro de la reglamentación, se permiten las comisiones variables ${ }^{16}$ con un límite máximo establecido entre seguros y comisiones del 3\%, no es posible evidenciar que las administradoras vía competencia hayan optado por menores costos generando un mayor abono a las cuentas individuales; no es una característica del mercado que las AFP abonen a las cuentas excedentes por menores costos o que implementen comisiones diferenciales, las cuales se permiten dentro de la reglamentación. Del 3\% límite para seguros y comisión, en algunos casos se puede ver que se destina incluso un porcentaje mayor como comisión de administración que el porcentaje trasladado por

16 En el artículo 7 de la Ley 797 de 2003 que modifica el artículo 20 de la Ley 100 de 1993, se establece que la reducción en los costos de administración y las primas de los seguros de invalidez y sobrevivencia deberá abonarse como un mayor valor en las cuentas de ahorro pensional de los trabajadores afiliados. 
concepto de seguros, aun teniendo en cuenta que estos tienen a cargo el pago de las pensiones de invalidez y sobrevivientes.

Lo anterior se da puesto que, de acuerdo con la estructura del mercado, los afiliados parecen no ser sensibles a los precios (comisiones) y los cambios y elección de AFP se dan por otro tipo de mecanismos tales como la publicidad e influencia que los asesores de ventas puedan generar sobre los mismos, más que por variables relevantes de mercado. Esto también es producto de las fuertes asimetrías en la información y los niveles de conocimiento que se requerirían sobre el tema para tener algún poder o capacidad de decisión.

Existe un número de barreras a la entrada que dificulta la formación de nuevas AFP a pesar de la alta rentabilidad obtenida por las administradoras en este negocio. Sin embargo, la sola entrada de nuevos actores no asegura un impacto sobre las comisiones cobradas, pues la insensibilidad de la demanda al precio promueve que los esfuerzos de comercialización se centren en otras variables. Por tanto, desde el punto de vista de la eficiencia del sistema y de los costos sociales de proveer el servicio, la sola entrada a la industria sin medidas en favor de la elasticidad de demanda es insuficiente, pues no genera beneficios para los afiliados en la forma de menores precios. Una política de competencia en este mercado no puede centrarse en la premisa de que basta con que haya más firmas para que haya más competencia (Marcell, 2006, p. 55).

En estudios realizados sobre el tema, se confirma esta situación y se encuentra evidencia de que los afiliados responden más a estrategias de comercialización que a toma de decisiones sobre variables relevantes como comisiones cobradas ${ }^{17}$. Para el caso colombiano, es posible evidenciar tal comportamiento mediante el análisis de la estrategia asumida por Skandia a partir de 1995 con el cobro de comisiones diferenciales inferiores a las cobradas por otras AFP (las cuales siempre correspondían al máximo establecido para comisiones y seguros de invalidez y sobrevivencia), abonando un mayor valor de los aportes a la cuenta individual, sin que sea posible evidenciar durante este periodo un alto crecimiento en el número de afiliados en relación con las demás AFP, las cuales no implementaron esta estrategia de reducción en el valor de la comisión cobrada. 
De igual manera, después del año 2003, en el que abandona esta estrategia, no se ve afectado el crecimiento en el número de afiliados que pudiera reflejar efectos del precio sobre la decisión de los individuos acerca de la selección de la respectiva administradora de fondos de pensión, es decir, algún tipo de elasticidad de la demanda a precios del mercado. Durante el 2004, año siguiente al abandono de la estrategia, el crecimiento en su número de afiliados fue del 10\%, similar al de Protección y Porvenir, por encima incluso de Horizonte que presentó apenas un crecimiento del $6 \%$.

Frente a la afirmación de la concentración de la industria de AFP, en el caso colombiano es posible ver que a marzo de 2010 Horizonte, Porvenir y Protección cuentan con el $71 \%$ de los afiliados al sistema, y también registran el 71\% de los fondos de pensiones administrados en el régimen de ahorro individual, si se considera un índice frecuente de medición estadística conocido como el índice Herfindahl Hirschman $(\mathrm{HHI})^{18}$, el cual se basa en el número total y en la distribución de los tamaños de las firmas de una industria.

$\mathrm{HHI}=\sum(\mathrm{Si}) 2$, donde Si corresponde a la participación relativa de la enésima empresa.

De acuerdo con el valor de los fondos administrados por cada una de las AFP, obteniendo el índice HHI, se tiene lo siguiente:

Tabla 2. Índice Herfindahl - Hirschman

\begin{tabular}{|l|c|c|c|}
\hline \multicolumn{4}{|c|}{ Valor fondo de pensiones a marzo de 2010, valores en millones de pesos } \\
\hline \multicolumn{1}{|c|}{ AFP } & Fondos administrados 2010 & \% de participación (Si) & $\mathbf{S i}^{\wedge} \mathbf{2}$ \\
\hline Protección & 21.165 .368 & 22 & 0,048 \\
\hline Skandia & 4.028 .278 & 1 & 0,000 \\
\hline Skandia plan alternativo & 155.914 & 0 & 0,000 \\
\hline Colfondos & 11.934 .392 & 16 & 0,026 \\
\hline ING & 9.635 .041 & 12 & 0,014 \\
\hline Porvenir & 22.466 .723 & 31 & 0,096 \\
\hline Horizonte & 13.433 .663 & 18 & 0,032 \\
\hline Total & 82.819 .380 & & \\
\hline HHI & & & $\mathbf{0 , 2 1 7}$ \\
\hline
\end{tabular}

Fuente: construcción propia

18 Este índice se utiliza muy a menudo para medir la concentración de mercado que toma en cuenta el número de competidores y su participación en el mismo. 
La medida de este índice establece que entre más cercano a 1 la industria es más concentrada, y entre más cercano a 0 esta es más competitiva; un valor igual a 1 indicaría que la industria es un monopolio. En la literatura al respecto, se considera que un índice Herfindahl - Hirschman con un intervalo $0,18<\mathrm{HHI}<1$ significa la existencia de una industria altamente concentrada. De acuerdo con esto, el resultado obtenido indicaría que el nivel de concentración de la industria de AFP en Colombia es alto. Así mismo, como se muestra en el cuadro, Protección y Porvenir representan más de la mitad del mercado con el manejo del 53\% de los activos totales de los fondos de pensiones.

Con el aumento del grado de concentración de una industria y dada la falta de información y conocimiento del afiliado, difícilmente la competencia se dará por diferenciación en variables previsionales relevantes. De igual manera, los resultados en términos de ganancias pueden ser muy atractivos para las administradoras participantes, mas no muy favorables en términos de eficiencia social, y la concentración se puede constituir en una barrera para la entrada de nuevos participantes en el mercado.

\section{Estructura de comisiones, gastos y rentabilidad de las AFP}

Los patrimonios y contabilidad de las AFP están separados de los fondos de pensiones bajo su administración, de tal manera que los resultados obtenidos para cada uno de los patrimonios se maneja de manera independiente. Los ingresos de las AFP están representados principalmente en las comisiones cobradas por concepto de administración de los fondos. En términos absolutos, se tiene que para el año 2009 el sistema obtuvo ingresos por comisiones por 981.192 millones de pesos; de este valor, los ingresos por comisiones con mayor participación corresponden a los generados por la comisión de administración de aportes a pensión obligatoria, seguido de las comisiones cobradas por administración de recursos de afiliados cesantes, el cual presentó un crecimiento promedio anual del $61 \%$ durante el periodo 2000-2009, indicador de la significancia de los periodos en los que los afiliados no realizan aportes (figura 6). 
Figura 6. Ingreso de las AFP por concepto de comisiones de administración FPO

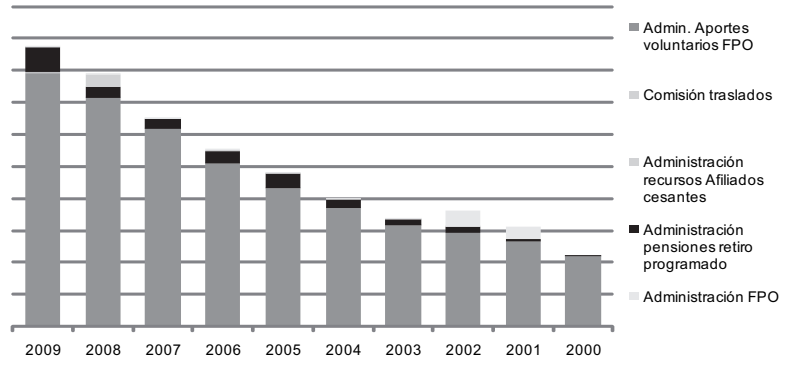

Fuente: Superintendencia Financiera de Colombia. Estados Financieros AFP

Los niveles de ingresos de las AFP por afiliado han mantenido crecimientos regulares durante los últimos diez años (7\% promedio anual). A precios de 2009, durante el periodo 2000-2009 se ha transferido a las AFP, por concepto de comisiones de administración en sus diferentes modalidades, un valor de 6,2 billones de pesos, valor que representa cerca del 9\% de los aportes realizados.

Si bien la literatura existente sobre los costos del mercado de AFP argumenta sobre la presencia de economías de escala y establece que se presentan retornos crecientes, es decir el costo del servicio de administración de los fondos de pensión es menor en relación con el aumento en los fondos administrados y con el incremento en el número de afiliados, y por tanto se podrían cobrar menores comisiones a los mismos, tal efecto o parte del mismo no ha sido transferido de manera alguna a los afiliados. En el sistema colombiano, al considerar la relación costo por activos administrados se tiene que el incremento de los costos es menor en relación con el incremento en los fondos administrados y en el número de afiliados. 
Figura 7. Costo por activos administrados en fondos de pensiones

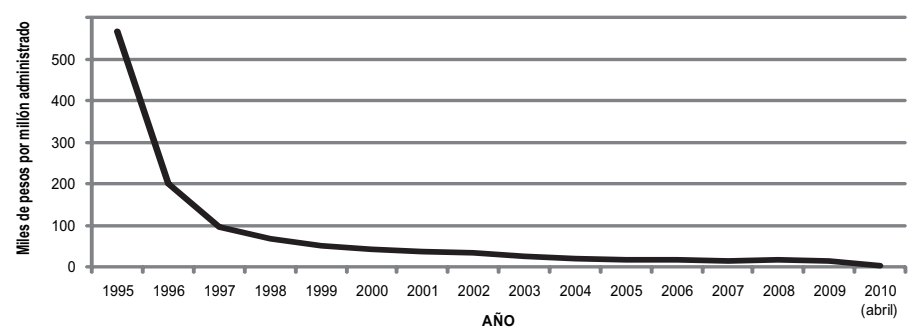

Fuente: Superintendencia Financiera de Colombia. Estados financieros AFP, estadísticas fondos de pensiones

De acuerdo con el gráfico anterior, el costo medio por recursos administrados ha presentado una tendencia decreciente en el tiempo; esta también podría ser indicativo de la existencia de barreras a la entrada por cuanto en el inicio de la actividad los costos medios resultan significativamente elevados. Es así como al comenzar el sistema las AFP participantes tuvieron que asumir utilidades negativas y con el aumento en el volumen de recursos administrados estas tienden a disminuir.

Haciendo referencia al concepto de eficiencia operativa, el cual también es un indicador de los resultados financieros de las AFP, de acuerdo con los resultados para el año 2009, los gastos operacionales constituyen aproximadamente un 67\% de los ingresos operacionales percibidos por las AFP, esto aun considerando los elevados costos relacionados con personal, gastos de publicidad, gastos de viaje, relaciones públicas, entre otros. Si se observa su comportamiento desde los inicios del sistema, es posible evidenciar que se ha logrado eficiencia administrativa representada en la mejora de las utilidades obtenidas por los accionistas de estas entidades: sin embargo, esto no es representativo de eficiencia del sistema en general, por cuanto nada de estos beneficios se ha transferido a los afiliados. 
Figura 8. Eficiencia operacional de las administradoras de fondos de pensiones desde el inicio del sistema

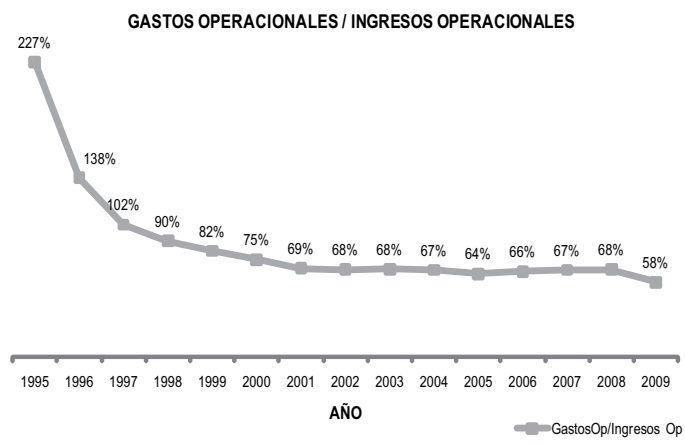

Fuente: Superintendencia Financiera de Colombia. Estados Financieros AFP

Como se muestra en la figura 8, el sistema ha ganado en términos de eficiencia, aun considerando que los gastos operacionales que presentan este tipo de compañías son elevados, especialmente los que tienen que ver con personal y mercadeo. En 2009, los estados financieros del sistema en conjunto mostraron que los gastos de publicidad, propaganda, relaciones públicas y viaje significaron alrededor de 43 mil millones de pesos, esto sumado a los gastos de personal y honorarios para el año en mención, ascendieron a la suma de 397 mil millones de pesos.

Las administradoras de fondos de pensiones y cesantías se caracterizan por ser las entidades del sector financiero con mayores rentabilidades; en los últimos diez años sus utilidades han crecido el $25 \%$ promedio anual, ganancias derivadas de las comisiones cobradas por los recursos administrados. Esto contrasta con las rentabilidades reales de los fondos de los afiliados, sin considerar rentabilidad neta de comisiones, que están en el orden del $11 \%$.

Una forma de ilustrar la importancia de las comisiones cobradas para las AFP es comparando el monto de las comisiones cobradas con las utilidades netas de las AFP. Para el año 2009 , alrededor del $41 \%$ de los ingresos por comisiones de administración de pensiones obligatorias se ven traducidos en utilidades, la tendencia se mantiene alrededor de este porcentaje desde el año 2000 cuando las administradoras empiezan a generar ganancias en eficiencia, puesto que en los primeros años de operación del sistema los márgenes de operación fueron bajos, negativos durante los años 1995-1997. 
El efecto de las comisiones de administración de pensiones obligatorias cobradas a los afiliados es altamente significativo sobre los ingresos operacionales que perciben las AFP; una variación del 0,1\% de la comisión cobrada puede significar para las administradoras un cambio en sus ingresos operaciones alrededor del 7\%. Así, aunque el efecto de variación de un 0,1 en la comisión de manera individual no tiene fuertes impactos desde el punto de vista de las decisiones de afiliación, sí lo tiene en gran medida sobre las utilidades de las AFP, razón que puede explicar por qué no se usan comisiones diferenciales con un mayor abono a las cuentas del afiliado.

En cuanto a utilidades se refiere en los últimos diez años, 2000-2009, las administradoras de fondos han obtenido utilidades netas de aproximadamente 2,5 billones de pesos ${ }^{19}$, lo que representa, como se indicó anteriormente, el $41 \%$ de lo cobrado por comisiones de administración de pensiones obligatorias, esto sin contar las utilidades originadas en el sistema obtenidas por las compañías de seguros, con quienes se contrata el pago de pensiones, recursos que se transfieren desde el afiliado-pensionado como concepto de costos asociados a la administración de sus ahorros de jubilación. En este mismo periodo se transfirieron por concepto de comisiones cerca del $8 \%$ del total de aportes al sistema, que junto con las transferencias realizadas en el periodo por seguros de invalidez y sobrevivencia, alcanza el $15 \%$ de los aportes efectuados al RAI. De igual manera, se observa que únicamente por el concepto de administración se transfirió un mayor valor a las administradoras de fondos de pensiones que lo transferido a las aseguradoras que tienen que hacerse cargo del pago de las pensiones de invalidez y sobrevivencia. 
Tabla 3. Resultados AFP últimos diez años

\begin{tabular}{|c|c|c|c|c|c|c|c|}
\hline \multirow[b]{2}{*}{ Año } & \multirow{2}{*}{$\begin{array}{l}\text { Valor } \\
\text { fondo }\end{array}$} & \multicolumn{2}{|c|}{ Aportes } & \multicolumn{2}{|c|}{$\begin{array}{c}\text { Comisiones } \\
\text { transferidas a AFP }\end{array}$} & \multicolumn{2}{|c|}{ Utilidades AFP } \\
\hline & & $\begin{array}{l}\text { Millones } \\
\text { de pesos }\end{array}$ & $\begin{array}{c}\text { Millones } \\
\text { de pesos } \\
\text { (dic. 2009) }\end{array}$ & $\begin{array}{c}\text { Millones } \\
\text { de pesos }\end{array}$ & $\begin{array}{c}\text { Millones } \\
\text { de pesos } \\
2009\end{array}$ & $\begin{array}{l}\text { Millones } \\
\text { de pesos }\end{array}$ & $\begin{array}{c}\text { Millones } \\
\text { de pesos } \\
\text { (dic. 2009) }\end{array}$ \\
\hline 2000 & 5.409 .775 & 2.096 .191 & 3.677 .128 & 258.959 & 454.264 & 79.829 & 140.035 \\
\hline 2001 & 7.990 .306 & 2.702 .695 & 4.359 .592 & 322.993 & 521.004 & 146.433 & 236.204 \\
\hline 2002 & 15.704 .678 & 4.524 .210 & 6.779 .185 & 311.832 & 467.256 & 163.654 & 245.223 \\
\hline 2003 & 20.354 .457 & 4.838 .509 & 6.776 .463 & 335.758 & 470.238 & 147.976 & 207.244 \\
\hline 2004 & 26.467 .014 & 5.219 .767 & 6.864 .893 & 398.405 & 523.972 & 163.537 & 215.080 \\
\hline 2005 & 36.589 .847 & 6.213 .486 & 7.745 .786 & 481.315 & 600.012 & 210.147 & 261.972 \\
\hline 2006 & 43.314 .262 & 7.521 .353 & 8.942 .475 & 552.824 & 657.277 & 225.298 & 267.867 \\
\hline 2007 & 51.119 .239 & 9.374 .060 & 10.667 .345 & 652.337 & 742.336 & 234.161 & 266.466 \\
\hline 2008 & 58.379 .128 & 11.163 .727 & 12.019 .985 & 761.518 & 819.927 & 245.606 & 264.444 \\
\hline 2009 & 79.897 .622 & 13.778 .751 & 13.778 .751 & 981.192 & 981.192 & 454.890 & 454.890 \\
\hline Total & & 67.432 .749 & 81.611 .603 & 5.057 .133 & 6.237 .479 & 2.071 .530 & 2.559 .424 \\
\hline \multicolumn{3}{|c|}{$\%$ sobre aportes } & $100 \%$ & & $8 \%$ & & \\
\hline \multicolumn{7}{|c|}{ utilidades/comisiones } & $41 \%$ \\
\hline
\end{tabular}

Fuente: Superintendencia Financiera de Colombia

De acuerdo con los resultados presentados, las utilidades que obtuvieron las AFP sobre activos se han ubicado alrededor del $20 \%$, rentabilidad nada despreciable, máxime cuando el promedio del sistema financiero en los últimos años ha estado por debajo del 5\%. Así mismo, respecto a las utilidades obtenidas por las AFP sobre su patrimonio, se tiene que en promedio en los últimos siete años los niveles de rentabilidades generadas han sido del $25 \%$, mientras que el promedio reportado por la Superintendencia Financiera ${ }^{20}$ para las entidades vigiladas por este ente es cercano al $10 \%$.

20 Superintendencia Financiera. Histórico de resultados del sistema financiero colombiano. 
Tabla 4. Rentabilidad ROA y ROE de las administradoras de fondos de pensiones

\begin{tabular}{|c|c|c|c|c|c|}
\hline \multicolumn{6}{|c|}{ ROA } \\
\hline & $\begin{array}{c}\text { Diciembre } \\
\text { de } 2005\end{array}$ & $\begin{array}{l}\text { Diciembre } \\
\text { de } 2006\end{array}$ & $\begin{array}{c}\text { Diciembre } \\
\text { de } 2007\end{array}$ & $\begin{array}{c}\text { Diciembre } \\
\text { de } 2008\end{array}$ & $\begin{array}{c}\text { Diciembre } \\
\text { de } 2009\end{array}$ \\
\hline $\begin{array}{l}\text { Otras sociedades } \\
\text { administradoras* }^{*}\end{array}$ & $3,5 \%$ & $2,6 \%$ & $2,3 \%$ & $2,4 \%$ & $2,8 \%$ \\
\hline $\mathrm{AFP}^{\star *}$ & $24,3 \%$ & $22,1 \%$ & $20,2 \%$ & $18,2 \%$ & $24,6 \%$ \\
\hline Sector financiero ${ }^{* * *}$ & $6,9 \%$ & $2,5 \%$ & $2,6 \%$ & $2,3 \%$ & $6,7 \%$ \\
\hline \multicolumn{6}{|c|}{ ROE } \\
\hline & $\begin{array}{l}\text { Diciembre } \\
\text { de } 2005\end{array}$ & $\begin{array}{l}\text { Diciembre } \\
\text { de } 2006\end{array}$ & $\begin{array}{l}\text { Diciembre } \\
\text { de } 2007\end{array}$ & $\begin{array}{l}\text { Diciembre } \\
\text { de } 2008\end{array}$ & $\begin{array}{c}\text { Diciembre } \\
\text { de } 2009\end{array}$ \\
\hline $\begin{array}{l}\text { Otras sociedades } \\
\text { administradoras }^{*}\end{array}$ & $22,8 \%$ & $17,3 \%$ & $15,0 \%$ & $16,2 \%$ & $17,0 \%$ \\
\hline $\mathrm{AFP}^{\star *}$ & $29,2 \%$ & $25,9 \%$ & $23,8 \%$ & $21,8 \%$ & $30,3 \%$ \\
\hline Sector financiero $^{* * *}$ & $14,1 \%$ & $6,2 \%$ & $5,8 \%$ & $5,2 \%$ & $14,0 \%$ \\
\hline
\end{tabular}

Fuente: Superintendencia Financiera de Colombia

Las administradoras, año a año, obtienen su ingreso independiente de la gestión realizada en la administración sobre los ahorros de los afiliados. Los excedentes generados por las AFP y las ganancias en eficiencia se distribuyen entre los accionistas de las mismas sin que signifique algún beneficio para los afiliados y sin que las sociedades asuman algún tipo de riesgo, ya que este va por cuenta del afiliado. Así, por ejemplo, en 2007 y 2008, años en los que los fondos presentaron pérdidas, las AFP generaron importantes utilidades. En marzo de 2008, por ejemplo, mientras que las administradoras ganaban alrededor de 47.851 millones de pesos, los fondos de pensiones perdían en este mismo mes 1,5 billones de pesos, habiendo perdido de igual manera, en este mismo mes en el año 2007, 550 mil millones de pesos. En el año 2007 los fondos de pensiones reportaron ganancias por 3,5 billones; no obstante, en tan solo tres meses (primer trimestre de 2008) los fondos tuvieron pérdidas aproximadamente por 5 billones de pesos.

Independiente de que se afirme que las pérdidas ocurridas luego se compensan con rendimientos positivos generados, los resultados del sistema no se presentan tan claramente 
satisfactorios para los afiliados, más aun cuando son sus cuentas las que se encuentran continuamente expuestas al comportamiento y volatilidad de los mercados financieros. Por el contrario, en el caso de las administradoras, la disminución de costos por activos administrados permiten que obtengan altas utilidades y con esto elevados retornos sobre activos y patrimonio. Así mismo, los altos márgenes de utilidades permiten que se tengan importantes gastos en marketing y publicidad, gastos que dadas las características del mercado son los que les permiten competir por la captación de afiliados.

\section{El mercado de las aseguradoras}

La mayor parte de las pensiones del sistema son pagadas por las compañías de seguros. De acuerdo con el promedio del sistema, de las cotizaciones realizadas por el afiliado, el $1,42 \%$ se transfiere a las compañías de seguros para el pago de seguros previsionales por invalidez y sobrevivencia; asimismo, con estas compañías se contratan las pensiones bajo la modalidad de renta vitalicia.

Las primas emitidas corresponden al valor que se cobra anticipadamente por las aseguradoras en el momento en el que se contrata una renta vitalicia. Por su parte, los siniestros incurridos corresponden a las mesadas pagadas a los beneficiarios. En el gráfico siguiente se presenta la evolución de las primas emitidas respecto a los siniestros incurridos por año, observándose que a diciembre de 2009 la siniestralidad incurrida sobre primas emitidas ha sido del $23 \%$ promedio anual; la tendencia de esta relación ha sido creciente, lo que muestra el grado de maduración del sistema, que es de esperarse, teniendo en cuenta el acelerado crecimiento de la población mayor de 40 años. 
Figura 9. Primas emitidas - siniestros incurridos rentas vitalicias

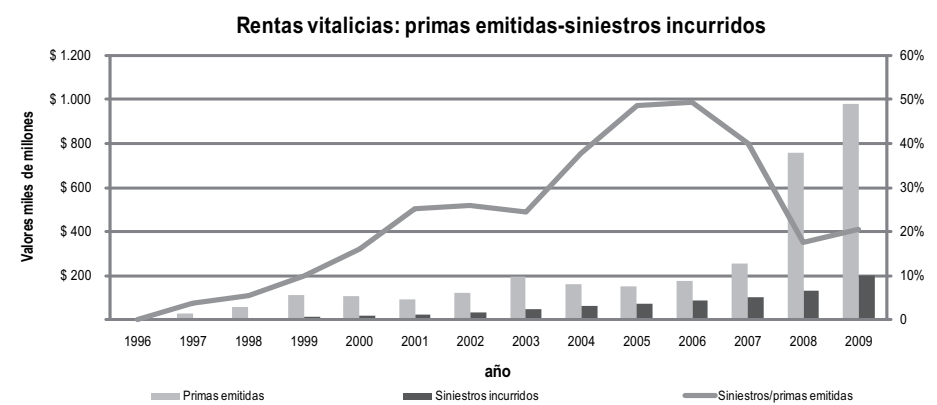

Fuente: Superintendencia Financiera de Colombia. Información estadística y financiera por ramos de seguros

Otro elemento importante relacionado con las rentas vitalicias lo constituyen las reservas matemáticas, las que presentan un importante crecimiento, esto máxime cuando en cada año los siniestros incurridos representan menos del 50\% de las primas emitidas. Así mismo, estas reservas ganaron importancia en su participación en el total de reservas de las compañías de seguros de vida, pasando del 41\% en el año 1998 a cerca del 80\% en el 2009.

Figura 10. Reservas matemáticas vs. total reservas de vida

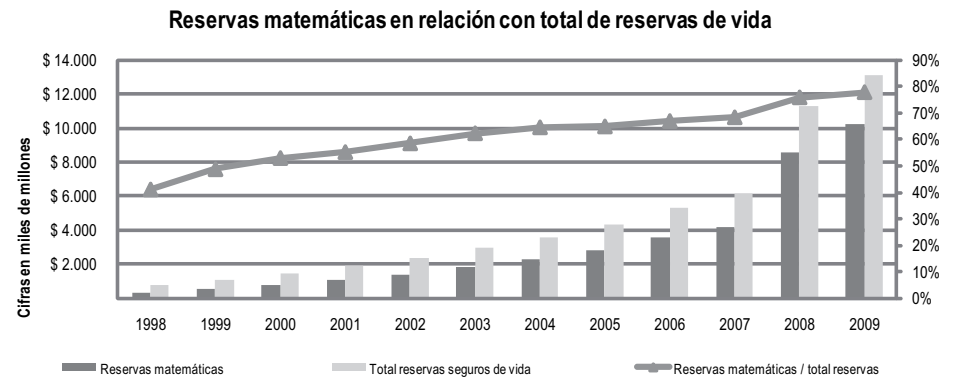

Fuente: Superintendencia Financiera, información de aseguradoras e intermediarios de seguros

De otra parte, la distribución del manejo de reservas matemáticas de pensión entre las aseguradoras se presenta como sigue: 
Figura 11. Distribución de reservas en las compañías de seguros de vida a diciembre de 2009

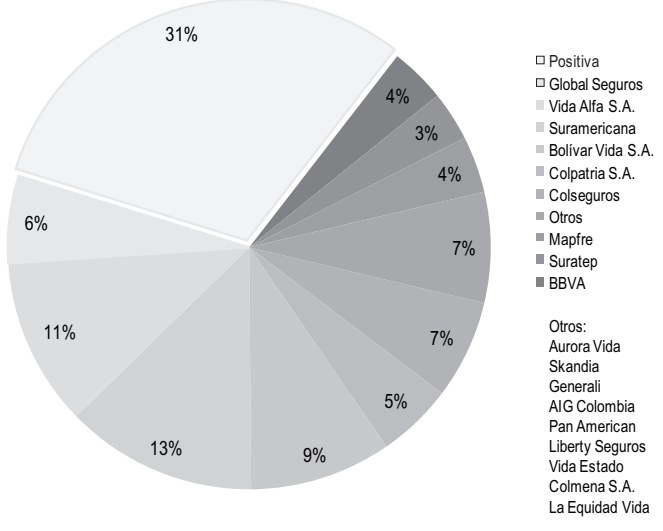

Fuente: Superintendencia Financiera

Aunque a diciembre de 2009 en el mercado asegurador se encuentran diecinueve compañías con reservas matemáticas, el $82 \%$ de las reservas concentra en siete aseguradoras. Suramericana, Seguros Alfa, Positiva y Seguros Bolívar tienen la mayor participación en el sector, $64 \%$ de las reservas administradas.

En 2009, los costos de intermediación en el ramo de seguridad social, definido como comisiones/primas, ha estado alrededor del 12\%. También, el sector presenta buenos resultados en términos de eficiencia, gastos generales/primas, los cuales han estado alrededor del $22 \%$, dado el crecimiento que vienen experimentando estas últimas.

Durante los últimos años (2000-2009), por concepto de seguros previsionales se han transferido a las compañías aseguradoras cerca de 5,4 billones de pesos (precios 2009), mientras que estas compañías han pagado pensiones cubiertas por el seguro por 4 billones, con excedentes del $25 \%$ de los recursos transferidos. De otra parte, se han trasladado por concepto de primas para el pago de rentas vitalicias 3,5 billones, y se han pagado por este concepto 926.691 millones, dándose una transferencia de primas netas anticipadas por 2,6 billones de pesos. Entre los excedentes generados por concepto de seguros de invalidez y sobrevivencia y las comisiones de administración pagadas a las AFP, se tiene que desde los afiliados se han transferido en este periodo 15,2 billones de pesos, aproximadamente el 19\% de los aportes realizados por aquellos. 
En términos generales, parece ser que quienes obtienen los mejores resultados son las administradoras de los fondos de pensión, que en los últimos años recibieron cerca de 6 billones de pesos, cifra muy superior que lo que se transfiere a las aseguradoras por seguros previsionales, máxime cuando estas últimas tienen que hacerse cargo del pago de las pensiones de invalidez y sobrevivencia. Pero para quienes definitivamente no parecen tan claros los beneficios del régimen es para los afiliados.

\section{Conclusiones}

Expuestos algunos de los resultados del régimen de ahorro individual en Colombia generados para los afiliados y esbozadas algunas condiciones de los beneficios que el sistema produce para la entidades administradoras de fondos de pensión, AFP, es posible afirmar que mientras los afiliados asumen todo el riesgo financiero, las ganancias en eficiencia no se redistribuyen en el sistema; esto es, no se traducen en menores precios para los afiliados y mayores valores abonados a las cuentas individuales, tal como se argumentó en el momento de la reforma. Al considerar a los actores en conjunto, es posible observar que se realizan transferencias considerables por concepto de administración que determinan altos excedentes para las administradoras y compañías de seguros, mientras que los afiliados ven reducidos sus saldos por los costos involucrados y asumen de manera individual los riesgos involucrados del manejo financiero de sus recursos y comportamiento de los mercados.

Frente a los beneficios para los afiliados, no hay evidencia de mayor cobertura ni mejores condiciones de jubilación; mientras tanto, las utilidades obtenidas por las AFP sobre activos se ubican alrededor del $20 \%$ y sobre el patrimonio en los últimos siete años los niveles fueron en promedio del $25 \%$, rentabilidades que no obtiene ningún sector de la economía y que están por encima incluso de las que obtiene en promedio todo el sistema financiero.

Aunque no fue objeto de este escrito, las presiones sobre el presupuesto de la Nación en el tema pensional tampoco se resolvieron por la introducción del régimen de ahorro individual, dadas las garantías otorgadas por el Estado, constituyéndose este en garante de última instancia frente al tema previsional en pensiones.

En el esquema de capitalización se debe considerar la reducción de los costos de administración y la forma en que las ganancias en eficiencia y beneficios puedan traducirse en aumento de las contribuciones a las cuentas individuales de los afiliados. 
Como se indicó, ya son varios los estudios que exhiben las debilidades del esquema de capitalización individual, y aunque de lo primero que se habla al plantear una reforma al sistema de pensiones son los aumentos en las edades de jubilación, esto no va a ser la solución porque tampoco es el problema principal. La seguridad social se debe pensar de manera integral dada su complejidad, teniendo en cuenta a todos los actores y hacia dónde deben dirigirse los beneficios del sistema. Los debates y aproximaciones teóricas deben considerar las múltiples variables estructurales que intervienen, pero lo más importante es que el análisis del sistema debe partir de establecer interrelación de medios con objetivos, puesto que resultan muy contradictorios los niveles de causalidad que se establecen para argumentar algunas de las medidas que se han adoptado.

En el tema de pensiones, es precisamente el cambio en las estructuras laborales con altos grados de flexibilización, que torna el concepto de seguridad social en pensiones hacia los sistemas de capitalización, donde de manera individual el afiliado debe asumir la responsabilidad y riesgo del ahorro de recursos para su vejez. No obstante, para el sostenimiento y efectividad de estos sistemas se hacen necesarias carreras laborales continuas, es decir estabilidad laboral, no garantizada por el alto grado de flexibilización y, además, por niveles salariales suficientemente elevados, los cuales, dados los altos niveles de desempleo, son cada vez menores.

En la estructuración y calidad de un sistema de seguridad social de ingresos para la vejez debe establecerse una valoración de la exposición al riesgo de los afiliados al mismo y revisar el marco de los principios y derechos sociales que deben definir el sistema de seguridad social. Con la implementación del esquema de multifondos se debe evaluar si efectivamente el afiliado lograría acumular los recursos necesarios para pensión al decidir no exponerse al riesgo en condiciones de inversiones moderadas, o es asumir el riesgo lo que está determinando las condiciones previsionales de la clase trabajadora del país; es decir, las evaluaciones al sistema deben establecer hasta qué punto es necesario apostar en ambientes de incertidumbre para que se tenga el derecho a una pensión de vejez.

Para la eficiencia del sistema es prioridad que dentro de la operación del mismo se mejoren los mecanismos para brindar información a los usuarios, para que estos tengan alguna capacidad de decisión frente a las estrategias comerciales que buscan inducir la elección de una determinada opción y para que ellos tengan la facultad de ejercer algún poder sobre el desempeño y direccionamiento del sistema. 


\section{Referencias}

Aguila, E., Attanasio, O. \& Quintanilla, X. (2010). Cobertura del sistema privado de capitalización en Chile, Colombia y México. Recuperado en http://www.rand.org/ pubs/working_papers/2010/RAND_WR642.pdf. el 23 de septiembre.

Berstein, S., Larrain, G. \& Pino, F. (2005, noviembre 30). Cobertura, densidad y pensiones en Chile, proyecciones a 20 años plazo. Santiago, Chile: Superintendencia de Administradoras de Fondos de Pensiones.

Bertranou, F.M. (2004, agosto). Reforma a los sistemas de jubilaciones y pensiones en América Latina: paradigmas y temas emergentes. Oficina Internacional del Trabajo. Oficina Subregional para el Cono Sur de América Latina. Disponible en www.oitchile.cl

Borrero Restrepo, L.H. (2003, septiembre 30). Congreso "de la seguridad social a la protección social avance o retroceso" 10 años de la Ley 100 1993-2003. Superintendencia Bancaria de Colombia.

Castro, R. (2005, agosto). Efectos de largo plazo de la comisión fija en el sistema chileno de AFP.Santiago, Chile: Superintendencia de Administradoras de Fondos de Pensiones.

Congreso de la República de Colombia.(1993). Ley 100 por la cual se crea el sistema de seguridad social integral y se dictan otras disposiciones.

Congreso de la República de Colombia.(2003). Ley 797 por la cual se reforman algunas disposiciones del sistema general de pensiones previsto en la Ley 100 de 1993 y se adoptan disposiciones sobre los regímenes pensionales exceptuados y especiales.

Contraloría General de la República. (2008). Informe financiero. Informe especial. El régimen de ahorro individual en pensiones. Bogotá, Colombia.

Devesa, J.E., Carpio, R. \& Vidal M., C. (2002). Assessing Administration charges for the affiliate in individual account systems. Instituto Valenciano de Investigaciones Económicas S.A.

Devesa, J.E., Martínez, M. \& Vidal, C. (2000). Análisis y valoración de los sistemas de pensiones reformados en Latinoamérica. Valencia, España: Instituto Valenciano de Investigaciones Económicas. 
Devesa, J.E., Rodríguez, R. \& Vidal, C. (2002). Los costes de administración para el afiliado en los sistemas de pensiones basados en cuentas de capitalización individual: medida y comparación internacional.Valencia, España: Departamento de Economía Financiera y Matemática. Facultad de Economía, Universidad de Valencia.

Fedesarrollo. (2010). El sistema pensional en Colombia: retos y alternativas para aumentar la cobertura. Recuperado el 23 de septiembre de 2010 de http://www.asofondos.org.co/VBeContent/library/documents/DocNewsNo57DocumentNo191.pdf

Ferro, G. (2002). Regulación y costos variables endógenos en el mercado de fondos de jubilaciones y pensiones argentino. Tesis doctoral en economía. Argentina: Universidad del CEMA. Disponible en http://www.cema.edu.ar/publicaciones/download/ documentos/231.pdf

Goldberg, L., Lo Vuolo, R.M. (2005). La reforma de la reforma. Un nuevo sistema previsional para la Argentina. Buenos Aires, Argentina: Centro Interdisciplinario para el Estudio de Políticas Públicas. Documento de trabajo No. 45.

Harris, A.R., Sabelhause, J. \& Simpson, M. (2005). Social security benefit uncertainty under individual accounts. Wastern Economic Association International.

Holzman, R. \& Hinz, R. (2005). Soporte del ingreso en la vejez en el siglo veintiuno. Una perspectiva internacional de los sistemas de pensiones y de sus reformas. Banco Mundial.

Marcell Cullel, M.(2006). Documento de reforma al sistema pensional en Chile. Consejo Asesor para la reforma pensional. Ministerio de Hacienda.

Reveiz, L. \& Piraquive. (2009). Modelo de simulación del valor de la pensión de un trabajador en Colombia. En Borradores de Economía. Bogotá: Banco de la República.

Riesco, M. (2007). Resultados para los afiliados de las AFP y compañías de seguros relacionadas con la previsión 1982-2006. Chile: Centro de Estudios Nacionales de Desarrollo Alternativo.

Suárez R., A., Acosta A., C., Meza, C. \& Cabra, F. (2007). Determinantes de la afiliación al sistema general de pensiones en las diez áreas metropolitanas 1996 y 2006. Bogotá, Colombia: DANE. 